\title{
Post-infarction ventricular septal rupture
}

\section{Tirone E. David}

Division of Cardiac Surgery of the Peter Munk Cardiac Centre at Toronto General Hospital and the University of Toronto, Toronto, Ontario, Canada

Correspondence to: Tirone E. David, MD. Division of Cardiac Surgery of the Peter Munk Cardiac Centre at Toronto General Hospital and the University of Toronto, 200 Elizabeth St. 4N453, Toronto, Ontario M5G 2C4, Canada. Email: tirone.david@uhn.ca.

\begin{abstract}
Coronary reperfusion therapies have led to a reduction in the incidence of mechanical complications of acute myocardial infarction (AMI), but the associated mortality of these complications has remained high. Ventricular septal rupture is the most common mechanical complication after myocardial infarction and occurs in approximately $0.21 \%$ with ST-segment elevation myocardial infarction and in $0.04 \%$ with nonST-segment elevation myocardial infarction. Surgery is the only definitive treatment but it is associated with high operative mortality and morbidity and, in some centers, alternative treatment with mechanical support of circulation and trans-catheter closure of the defect is being used. We continue to believe that immediate surgery offers the best opportunity for long-term survival. Patients should be taken directly to the operating room or via the heart catheterization laboratory if the coronary artery anatomy is unknown. This should be done as soon as the diagnosis is made, as acute rupture of the interventricular septum is a surgical emergency. The operative technique of infarct exclusion has been our preferred method and when performed in hemodynamically stable patients, the operative mortality is around $10 \%$, although much higher in patients in cardiogenic shock. Patch dehiscence and persistent shunts are uncommon after closure of the defect using this technique. Delaying operative intervention in hemodynamically stable patients frequently leads to cardiogenic shock and multi-organ failure. Transcatheter closure of these acute septal lesions is complex, not necessarily feasible in all patients, and there is no evidence that the results are superior to surgery.
\end{abstract}

Keywords: Acute myocardial infarction (AMI); mechanical complications of myocardial infarction; postinfarction ventricular septal rupture

Submitted Jun 23, 2021. Accepted for publication Nov 08, 2021.

doi: 10.21037/acs-2021-ami-111

View this article at: https://dx.doi.org/10.21037/acs-2021-ami-111

\section{Introduction}

Surgery for mechanical complications of acute myocardial infarction (AMI) used to be common when I started practicing four decades ago (1), and I was able to accumulate considerable experience in this field and subsequently developed a novel approach to treat a ruptured interventricular septum $(2,3)$. The emergence of coronary artery reperfusion therapies have reduced the frequency of mechanical complications of AMI but the mortality rate has remained high (4). In a recent report by Elbadawi and colleagues (4) based on The National Inpatient Sample (NIS) database from 2003 through 2015, mechanical complications of AMI occurred in $0.27 \%$ of patients with ST-segment elevation myocardial infarction (STEMI) and in $0.04 \%$ after non-ST-segment elevation myocardial infarction (NSTEMI). However, the mortality was $42.4 \%$ in patients with mechanical complications of $\mathrm{AMI}$ and $12.7 \%$ in patients without, and this did not change during the period of observation (4). These poor outcomes are humbling but challenge us to seek better treatment alternatives for patients with mechanical complications of AMI.

STEMI is more likely to be associated with a transmural infarction than NSTEMI (5). A transmural AMI is a prerequisite for ventricular wall rupture and hence is more common after STEMI than NSTEMI $(4,5)$. 
Ventricular septal rupture is the most common type of mechanical complication after AMI $(1,4)$. In Elbadawi's report (4), of 13,767 patients who suffered mechanical complications, 10,344 (75\%) developed a ventricular septal defect (VSD) and the remaining patients developed mitral regurgitation due to ruptured papillary muscle (19\%) or free wall rupture $(6 \%)$. The most important determinant of outcome in post-infarction VSD is the development of heart failure (left, right, or both) and cardiogenic shock (2-5). The severity of heart failure is related to the extensiveness of myocardial necrosis and the left-to-right shunt. Cardiogenic shock in patients with anterior VSD is often associated with extensive left ventricular infarction and in patients with posterior VSD is associated with extensive right ventricular infarction (6-9). The magnitude of the shunt is also an important determinant of cardiogenic shock in both cases $(7,8)$. Although the diagnosis of post-infarction VSD can be made by auscultation of the heart, it may be difficult to differentiate from acute mitral regurgitation and a bedside trans-thoracic echocardiogram will usually confirm the diagnosis. Some degree of mitral regurgitation in patients with posterior VSD is common because of posterior wall and papillary muscle infarction. Medical treatment is ineffective and most patients die within 4 weeks (10). Thus, surgery or a catheter-based intervention is needed to save these patients. We believe that immediate surgery offers the best chance of survival after post-infarction VSD (3).

\section{Surgical treatment of post-infarction ventricular septal wall rupture}

Cooley and colleagues reported the first case treated with surgery using an approach through the right ventricular outflow tract (11). This approach does not offer adequate exposure of all parts of the septum and a few years later, most surgeons adopted an incision through the infarcted left ventricle (12). The location and length of the incision depends on where the defect is: apical, anterior or posterior septum. Daggett and colleagues from the Massachusetts General Hospital made important contributions to the surgical treatment of this lesion $(13,14)$. They introduced the concept of 'infarctectomy' and reconstruction of the interventricular septum and infarcted ventricular wall with Dacron patches (15). Apical VSDs were managed by apical amputation and approximation of the walls over strips of Teflon felt, and more extensive infarcts by infarctectomy and reconstruction of the septum and ventricular wall with separate patches of Dacron fabric (15).
In 1987 , we introduced a new operative procedure whereby no infarctectomy was done and the left ventricular cavity was largely excluded from the infarcted myocardium with a pericardial patch sutured to the endocardium of the left ventricle $(2,3)$. We coined the term 'infarct exclusion' to describe this approach and we continue to believe it is the best therapy for patients with an extensively infarcted septum, particularly in cases of posterior VSD. Apical VSD can be safely repaired as originally described by Daggett and associates (13-15), and this is illustrated in Figure 1.

\section{Infarct exclusion technique}

Myocardial revascularization should be done before septal repair in patients with multi-vessel coronary artery disease. If the VSD is associated with single vessel disease, surgical revascularization will depend on what was done percutaneously prior to the septal rupture. If the single diseased coronary artery was reopened by percutaneous coronary intervention (left anterior descending in anterior VSD and right coronary artery or dominant circumflex in posterior VSD), there is no need for bypass grafting. If the artery remains occluded, revascularization may be beneficial to improve left or right ventricular function. There is no point in bypassing an artery if it supplies only infarcted myocardium.

In patients with anterior VSD, an incision is made in the apex of the left ventricle 10 to $15 \mathrm{~mm}$ lateral to the path of the anterior descending artery, through the infarcted muscle, and extended just above where the septal defect is located. The margins of the infarcted septum and anterior wall are identified. A glutaraldehyde-fixed bovine pericardial patch is tailored in the shape of the left ventricular infarct. This patch is usually oval and measures approximately $4 \mathrm{~cm} \times 6 \mathrm{~cm}$ in most patients. The pericardial patch is then sutured to the lower part of the non-infarcted endocardium of the interventricular septum with a continuous 3-0 polypropylene suture as illustrated in Figure 2. The patch is also sutured to the non-infarcted endocardium of the anterolateral ventricular wall. If the infarct involves the base of the anterior papillary muscle, the suture is brought outside of the heart and buttressed on a strip of bovine pericardium or Teflon felt, applied to the epicardial surface of the left ventricle. Once the patch is completely secured to the endocardium of the left ventricle, the infarcted septum becomes largely excluded from the left ventricular cavity. The ventriculotomy is closed over two strips of bovine pericardium or Teflon felt, as illustrated in Figure 2. No 

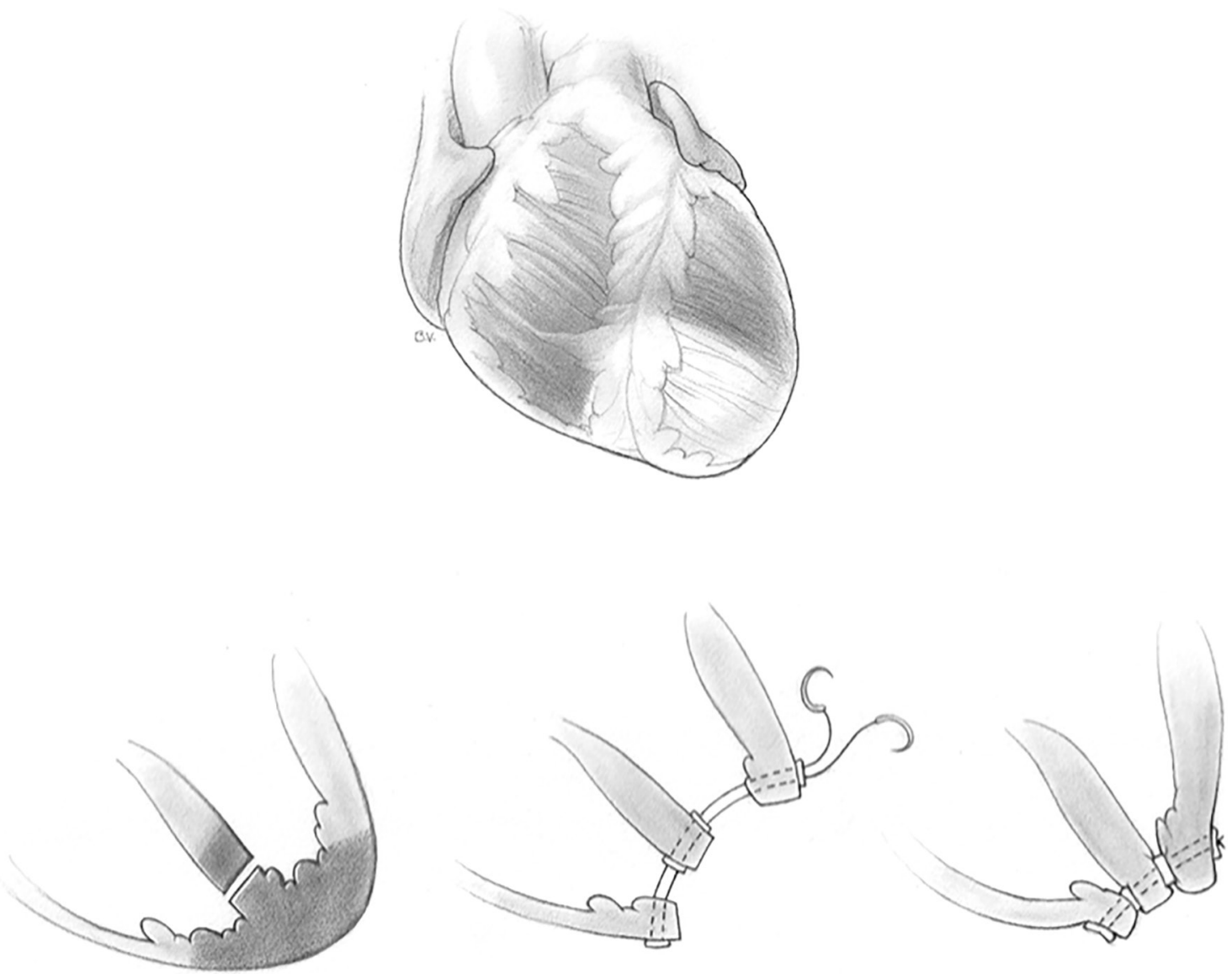

Figure 1 Repair of apical ventricular septal rupture. Simple amputation of the left ventricular apex and approximation of the left ventricular wall, septum and right ventricular wall without excessive compression of the tissues is often an effective treatment.

infarctectomy is performed unless the necrotic muscle along the ventriculotomy sloughs at the time of its closure. This area will be exposed only to right ventricular pressure once cardiopulmonary bypass is discontinued. The space between the patch and infarcted wall becomes obliterated within a few days.

In patients with posterior VSD, an incision is made in the base of the inferior wall of the left ventricle, $5 \mathrm{~mm}$ from the posterior descending artery. It should not be made further into the left side of the ventricle as the posterior papillary is adjacent and can be damaged. This incision starts at the base of the inferior wall, $2 \mathrm{~cm}$ from the atrioventricular junction, and extends proximally toward the mitral anulus and distally toward the apex of the ventricle. Stay sutures are passed through the fat pad of the apex of the ventricle to hold the heart upside and to the margins of the ventriculotomy to facilitate exposure of the ventricular cavity. The VSD is carefully located; it is usually in the proximal half of the posterior septum, close to the mitral valve and right ventricle. The posteromedial papillary muscle is often infarcted. A large bovine pericardial patch is used for repair. The patch is sutured to the fibrous anulus of the mitral valve with a continuous 3-0 polypropylene suture starting at the ventricular side of the central portion of $\mathrm{P} 2$ of the posterior leaflet of the mitral valve. Some chordae tendineae between the posterior leaflet and ventricular wall may have to be severed if they are obstructing the suture line. This suturing is carried along the fibrous mitral annulus to approximately the level of the medial commissure of the mitral valve, where the suture is interrupted. The large bovine pericardial patch is trimmed to fit the defect. Next, starting at the base of the septum, the patch is sutured to the endocardium of healthy septum towards the apex. The other side of the patch is sutured to the posterior wall of the left ventricle along a line corresponding to the medial margin of the posteromedial 

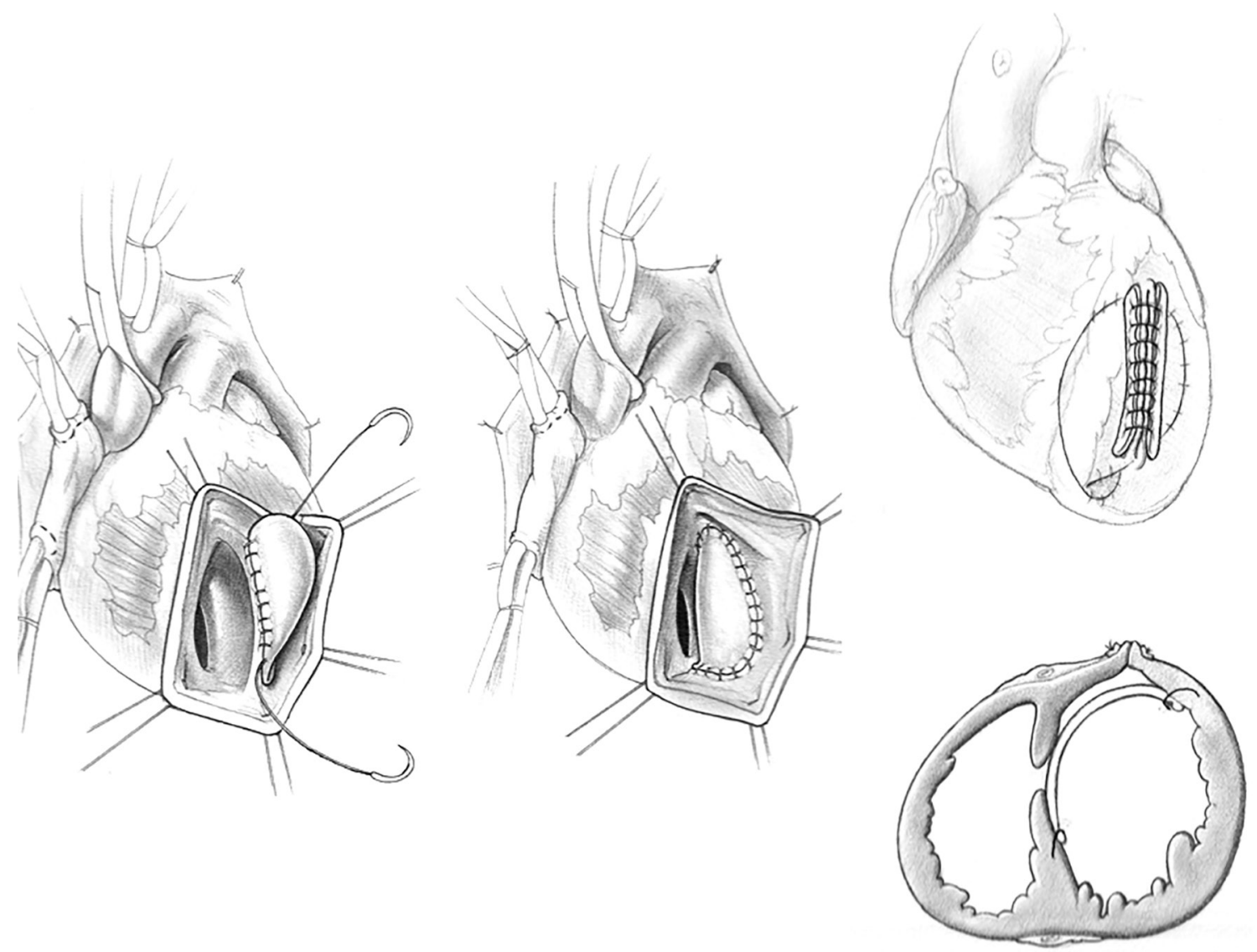

Figure 2 Repair of anterior ventricular septal rupture. An incision is made in the apex of the left ventricle through the infarcted muscle and extended up 10-15 mm away from the left anterior descending artery. A bovine pericardial patch is sutured to the endocardium of noninfarcted septum and anterior ventricular wall, excluding the infarcted septum. The ventriculotomy is closed without resecting any infarcted wall.

papillary muscle base. Given the posterior wall of the left ventricle infarct, it is necessary to use full-thickness bites and anchor the sutures on a strip of pericardium or Teflon felt applied on the epicardial surface of the posterior wall of the left ventricle, as shown in Figure 3. Once the patch is completely sutured to the distal part of the posterior wall, the sutures used to secure the patch to the septum and those used to secure the patch to the infarcted posterior wall are brought up toward the epicardium and tied to each other. The posterior wall ventriculotomy is then closed in two layers of sutures buttressed on strips of pericardium or Teflon felt. The infarcted right ventricular wall is left undisturbed. Occasionally, a patient may have severe mitral regurgitation and mitral valve replacement is necessary in such situations. We have done this only twice and in both instances, through the posterior wall ventriculotomy.
Figure 4 shows intra-operative photographs of the various stages of this operation.

\section{Trans-catheter closure of post-infarction ventricular septal wall rupture}

The first report of transcatheter closure of a post-infarct VSD was 1988 (16). This is a complex procedure and not all patients are candidates, particularly those with posterior VSD given their proximity to the mitral valve and complexity of the regional anatomy. Schlotter and colleagues (17) conducted a systematic literature review to evaluate the effectiveness of percutaneous closure of post-infarction VSD. They identified 13 series of more than 5 cases per report, for an overall 273 patients (17). Cardiogenic shock was present in $48 \%$ of cases, the timing 

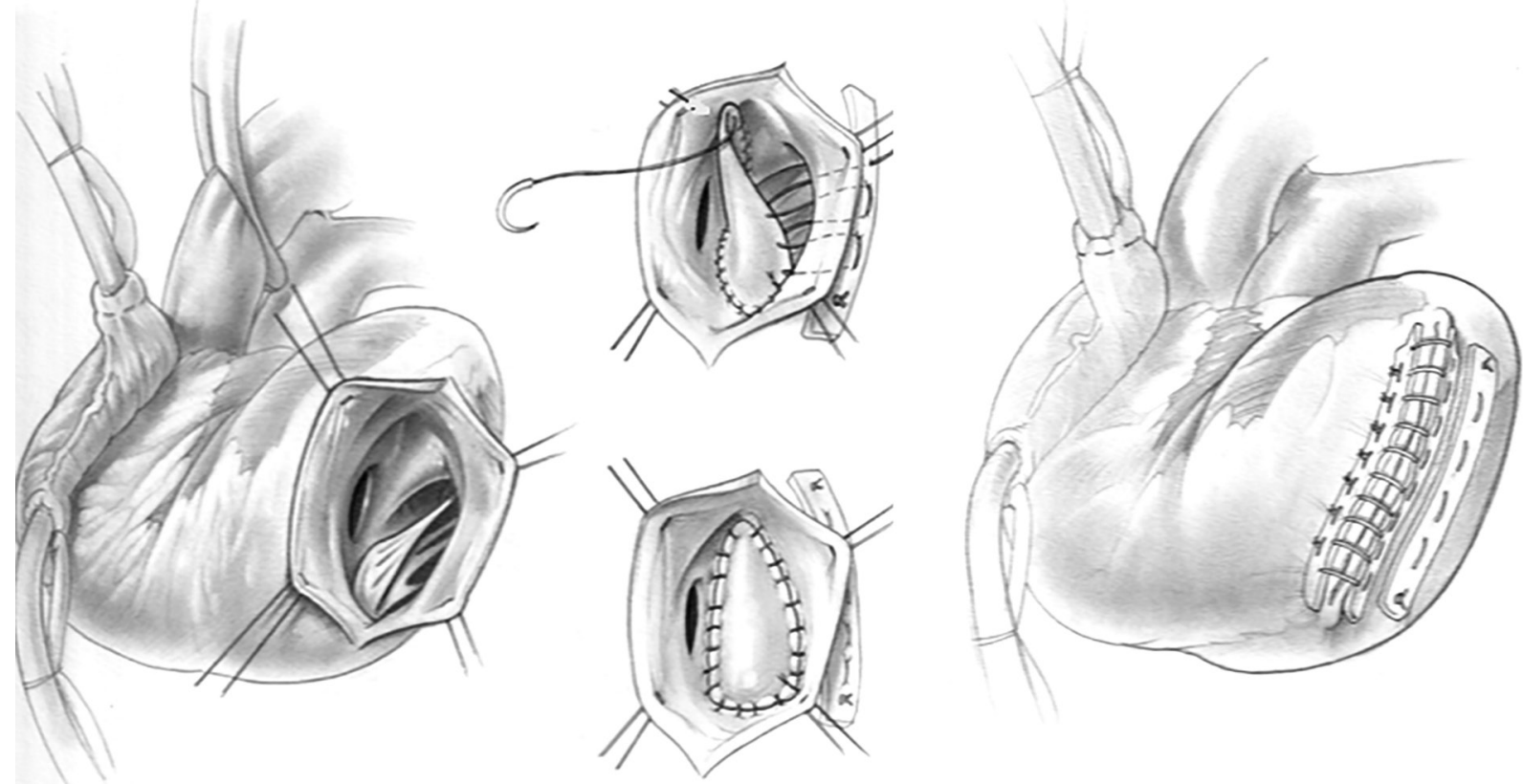

Figure 3 Repair of posterior ventricular septal rupture. The apex of the heart is secured to the upper part of the skin incision. An incision is made $5 \mathrm{~mm}$ from the posterior descending artery along the posterior left ventricular wall and extended proximally close to the mitral annulus and distally toward the apex. A bovine pericardial patch is sutured to the mitral annulus from its mid-portion and toward the medial commissure until healthy septum is identified. The medial part of the patch is sutured to the infarcted posterior wall using full thickness bites buttressed on a strip of bovine pericardium or Teflon felt on the epicardial surface immediately adjacent to the insertion of the posterior papillary muscle. The other side of the patch is sutured to the healthy endocardium of the septum. The ventriculotomy is closed without resecting any infarcted wall.

of the intervention was within 2 weeks from rupture in $42 \%$ and successful device implantation rate was $89 \%$. The in-hospital mortality rate in patients successfully treated was $32 \%$ (17). The authors concluded that transcatheter closure is an alternative to surgery in selected patients. Larger experience is needed before deciding if this is indeed as effective as surgery to treat post-infarction VSD, particularly in the long-term.

\section{Discussion}

A report on the surgical outcomes of post-infarction VSD based on the STS Database from 1999 through 2010 indicated that only 2,876 patients underwent surgery in 666 participating institutions with an average of 0.09 to 3.7 patients/year per cardiac unit (18). Thus, very few surgeons operate on more than one patient per year. The overall mortality was $42.9 \%$, higher in patients who had surgery within seven days from the AMI (54.1\% vs.
$18.4 \%)(18)$. I was the invited discussant of that paper and I pointed out that I had reviewed the surgical experience with post-infarction VSD at Toronto General Hospital from 1990 to 2010, with 91 patients identified. The overall operative mortality was $40 \%$, but nine surgeons performed the operations and mortality among surgeons ranged from $20 \%$ to $100 \%$-it appears to be related to the number of operations each surgeon performed. Two surgeons operated on 49 patients and nine died whereas seven surgeons operated on 43 patients and 22 died. Repetition makes perfect and it is difficult to gain experience with an operation that is now so rarely performed. In addition, these operations are difficult and likely cannot be mastered by most surgeons largely due to its rarity. Thus, in order to improve the outcomes of post-infarction VSD, patients should be referred to centers where both surgical and catheter-based techniques expertise are available $(19,20)$. I firmly believe that patients with post-infarction VSD should be operated on as soon as the diagnosis is made to prevent 

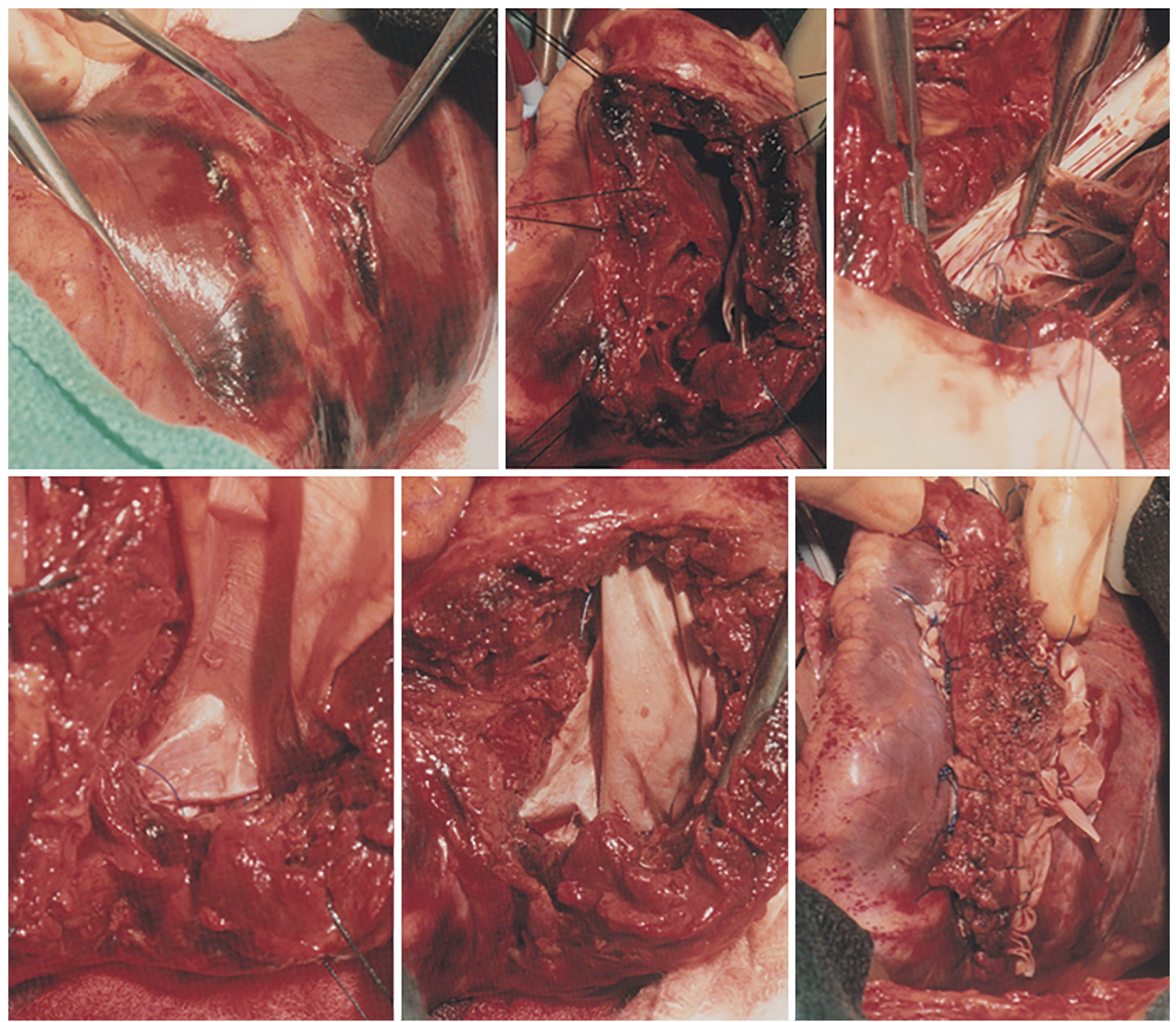

Figure 4 Intraoperative photographs of a ruptured posterior septum repair as described in Figure 3.

worsening of the clinical presentation. If the expertise to do that is not available, hemodynamically stable patients should be transferred to referral centers as soon as the diagnosis is established, and patients in cardiogenic shock should have a device implanted to mechanically support the circulation (Impella or venous-arterial extracorporeal membrane oxygenation) and then should be transferred to a large center. The probability that the above proposal for the management of these patients will come to fruition may be more utopic and realistic.

\section{Acknowledgments}

Funding: None.

\section{Footnote}

Conflicts of Interest: The author has no conflicts of interest to declare.

Open Access Statement: This is an Open Access article 
distributed in accordance with the Creative Commons Attribution-NonCommercial-NoDerivs 4.0 International License (CC BY-NC-ND 4.0), which permits the noncommercial replication and distribution of the article with the strict proviso that no changes or edits are made and the original work is properly cited (including links to both the formal publication through the relevant DOI and the license). See: https://creativecommons.org/licenses/by-nc-nd/4.0/.

\section{References}

1. Reddy SG, Roberts WC. Frequency of rupture of the left ventricular free wall and ventricular septum among necropsy cases of fatal acute myocardial infarction since introduction of coronary care units. Am J Cardiol 1989;63:906-11.

2. Komeda M, David TE. Surgical treatment of postinfarction false aneurysm of the left ventricle. J Thorac Cardiovasc Surg 1993;106:1189-91.

3. David TE, Dale L, Sun Z. Postinfarction septal rupture: repair by endocardial patch with infarct exclusion. J Thorac Cardiovasc Surg 1995:110:1315-22.

4. Elbadawi A, Elgendy IY, Mahmoud K, et al. Temporal Trends and Outcomes of Mechanical Complications in Patients With Acute Myocardial Infarction. JACC Cardiovasc Interv 2019;12:1825-36.

5. Goldberg RJ, Spencer FA, Gore JM, et al. Thirtyyear trends (1975 to 2005) in the magnitude of, management of, and hospital death rates associated with cardiogenic shock in patients with acute myocardial infarction: a population-based perspective. Circulation 2009;119:1211-9.

6. Fananapazir L, Bray CL, Dark JF, et al. Right ventricular dysfunction and surgical outcome in postinfarction ventricular septal defect. Eur Heart J 1983;4:155-67.

7. Zehender M, Kasper W, Kauder E, et al. Right ventricular infarction as an independent predictor of prognosis after acute inferior myocardial infarction. $\mathrm{N}$ Engl $\mathrm{J}$ Med 1993;328:981-8.

8. Moore CA, Nygaard TW, Kaiser DL, et al. Postinfarction ventricular septal rupture: the importance of location of infarction and right ventricular function in determining survival. Circulation 1986;74:45-55.

Cite this article as: David TE. Post-infarction ventricular septal rupture. Ann Cardiothorac Surg 2022;11(3):261-267. doi: 10.21037/acs-2021-ami-111
9. Cummings RG, Reimer KA, Califf R, et al. Quantitative analysis of right and left ventricular infarction in the presence of postinfarction ventricular septal defect. Circulation 1988;77:33-42.

10. Lemery R, Smith HC, Giuliani ER, et al. Prognosis in rupture of the ventricular septum after acute myocardial infarction and role of early surgical intervention. Am J Cardiol 1992;70:147-51.

11. Cooley DA, Belmonte BA, Zeis LB, et al. Surgical repair of ruptured interventricular septum following acute myocardial infarction. Surgery 1957;41:930-7.

12. Javid H, Hunter JA, Naiafi H, et al. Left ventricular approach for the repair of ventricular septal perforation and infarctectomy. J Thorac Cardiovasc Surg 1972;63:14-24.

13. Daggett WM, Buckley MJ, Akins CW, et al. Improved results of surgical management of postinfarction ventricular septal rupture. Ann Surg 1982;196:269-77.

14. Radford MJ, Johnson RA, Daggett WM Jr, et al. Ventricular septal rupture: a review of clinical and physiologic features and an analysis of survival. Circulation 1981;64:545-53.

15. Heitmiller R, Jacobs ML, Daggett WM. Surgical management of postinfarction ventricular septal rupture. Ann Thorac Surg 1986;41:683-91.

16. Lock JE, Block PC, McKay RG, et al. Transcatheter closure of ventricular septal defects. Circulation 1988;78:361-8.

17. Schlotter F, de Waha S, Eitel I, et al. Interventional postmyocardial infarction ventricular septal defect closure: a systematic review of current evidence. EuroIntervention 2016;12:94-102.

18. Arnaoutakis GJ, Zhao Y, George TJ, et al. Surgical repair of ventricular septal defect after myocardial infarction: outcomes from the Society of Thoracic Surgeons National Database. Ann Thorac Surg 2012;94:436-43; discussion 443-4.

19. Gong FF, Vaitenas I, Malaisrie SC, et al. Mechanical Complications of Acute Myocardial Infarction: A Review. JAMA Cardiol 2021;6:341-9.

20. Giblett JP, Jenkins DP, Calvert PA. Transcatheter treatment of postinfarct ventricular septal defects. Heart 2020;106:878-84. 